\section{Urbanização contemporânea e qualidade de vida para "cidades inteligentes": um debate a partir dos indicadores do IMRS na Microrregião de Araxá, Minas Gerais}

\author{
Contemporary urbanization and quality of life for "intelligent cities": discussion based on the IMRS \\ indicators in the Microregion of Araxá, Minas Gerais"
}

Josimar dos Reis de Souza *

Beatriz Ribeiro Soares **

\author{
*Doutorando no PPG em Geografia - UFU - josimarsouza@ufu.br. \\ ** Docente da Universidade Federal de Uberlândia - brsoares@ufu.br.
}

Recebido em 06/05/2018. Aceito para publicação em 25/06/2018.

Versão online publicada em 10/08/2018 (http://seer.ufrgs.br/paraonde)

\begin{abstract}
Resumo: Este estudo tem como foco a análise comparativa dos indicadores que constituem o Índice Mineiro de Responsabilidade Social (IMRS), dos anos de 2002 e 2012, disponibilizados pela Fundação João Pinheiro, tendo como escala de análise a Microrregião de Araxá (MG). Tem-se como foco analisar os indicadores buscando elencar a evolução da qualidade de vida, sob a perspectiva da utilização de bancos de dados existentes para a construção das chamadas "Cidades Inteligentes", projeto amplamente debatido na atualidade, na qual o uso de indicadores é indispensável. Os indicadores analisados foram: Saúde; Educação; Saneamento e Habitação; Renda e Emprego; e Finanças Municipais. A partir da tabulação de dados, espacialização cartografia e construção de gráficos, foi possível desenhar o panorama de evolução dos serviços públicos na microrregião e delinear apontamentos para a construção de ambientes urbanos mais saudáveis e inteligentes.
\end{abstract}

Palavras-chave: Urbanização Contemporânea. Qualidade de Vida. Cidades Inteligentes. IMRS.

\begin{abstract}
This study focuses on the comparative analysis of the indicators that make up the Minas Gerais Social Responsibility Index (IMRS) for the years 2002 and 2012, made available by the João Pinheiro Foundation, based on the analysis of the Microregion of Araxá (MG). The objective of this study is to analyse the indicators seeking to highlight the evolution of quality of life, from the perspective of the use of existing databases for the construction of so-called "Smart Cities", a widely debated project in which the use of indicators is indispensable. The indicators analysed were: Health; Education; Sanitation and Housing; Income and Employment; and Municipal Finance. From the tabulation of data, spatial mapping and construction of graphs, it was possible to draw the panorama of evolution of public services in the microregion and to outline notes for the construction of healthier and intelligent urban environments.
\end{abstract}

Key-words: Contemporary Urbanization. Quality of life. Smart Cities. IMRS.

\section{Introdução}

O presente estudo tem como objetivo analisar os indicadores que compõem o Índice Mineiro de Responsabilidade Social (IMRS) dos municípios da Microrregião de Araxá, Minas Gerais. Tal analise se alicerça na tendência dos estudos urbanos recentes, que visam a busca pela melhoria da qualidade de vida para a solução de problemas advindos da urbanização contemporânea. Na atualidade essa busca tem se centrado na melhoria da eficiência e eficácia do gerenciamento urbano, que tem se dado via implementação de bancos de dados inteligentes. Foco este do projeto "Cidades Inteligentes", desenvolvido a nível mundial e nacional (RBCIH, 2017).

A partir da análise do processo de urbanização no Brasil e os graves problemas sociais fica evidente a urgente necessidade de se buscar estratégias de intervenção para que as condições de 
vida da população sejam melhores. Nesse sentido, a busca por estratégias que garantam a melhoria das condições de saúde, seja física, mental, intrínseca ao indivíduo, como também, ao ambiente no qual está inserido, é de fundamental importância para se conquistar avanços na qualidade de vida e consequentemente alcançar níveis de inteligência coletiva.

O uso de variáveis e indicadores e sua análise integrada na constituição de índices são importantes na busca por ferramentas que auxiliem a gestão pública na tomada de decisões. Nesse sentido tem-se desenvolvido projetos no Brasil e no mundo, nos quais a análise estatística tem sido utilizada. Estudos realizados pela OMS, ONU, União Europeia, Rede Brasileira de Cidades Inteligentes e Humanas, entre outros, são exemplos mundiais na busca de sistema de indicadores que contribuíam com a melhoria do nível de vida no intraurbano (LIMA, 2013).

Nesse contexto, esse estudo visa trazer aparatos para a discussão das questões referentes a consolidação de banco de dados para a proposição de políticas públicas voltadas a melhoria da qualidade de vida da população e consequentemente a consolidação de uma rede de cidades "Inteligentes e Humanas". Para a análise aqui abordada foram utilizados os resultados do IMRS dos municípios que compõem a microrregião de Araxá (Minas Gerais), dos anos de 2002 e 2012 (optouse pelo intervalo de 10 anos, pois o IMRS mais recente diz respeito ao ano de 2012). Esses resultados foram tabulados, cartografados e elencados através de gráficos, para possibilitar a sua análise e demonstrar que essa ferramenta, criada pela Fundação João Pinheiro, possibilita resultados importantes para o gerenciamento das cidades, via banco de dados disponíveis. Justifica-se a escolha da microrregião de Araxá, por se tratar de região de atividade agropecuária e de mineração, com problemas urbanos relacionados a essas atividades econômicas.

\section{Urbanização Contemporânea, Qualidade de Vida e Cidades Inteligentes}

O rápido processo de urbanização vivenciado pelo Brasil no século XX, sobretudo pós 1950, fez com que o país até então com características predominantemente rurais passasse a conviver cotidianamente com a dinâmica econômica dos espaços urbanos e seus problemas sociais. Tais aspectos do processo histórico brasileiro apresentam-se como desafios para a superação das desigualdades e para o desenvolvimento social.

De acordo com Santos (1993), o movimento de urbanização, ocorrido após a Segunda Guerra Mundial, se deu por forte crescimento demográfico, resultado de elevados índices de natalidade e descenso de mortalidade, advindo de progressos sanitários e melhoria relativa nos padrões de vida, como também a própria urbanização. Tem-se então que o processo de urbanização no Brasil foi acompanhado por um grande crescimento populacional, diminuição da mortalidade, aumento da natalidade, ao êxodo rural, ao crescimento industrial, a busca por melhores condições de vida nas cidades, avanços na medicina, entre outros aspectos que levaram a constituição de novos valores e um modo de vida urbano. 0 conjunto desses fatores constituíram tecidos urbanos, com disparidades de acesso à renda, emprego, educação, saúde.

O Censo Demográfico do Instituto Brasileiro de Geografia e Estatística (IBGE, 2010) apresentou dados sobre o processo de urbanização no Brasil, nos quais tem-se que entre as décadas de 1940 e 1980, a taxa de urbanização do Brasil passou de 31,24\% para 67,59\%, em 1991 atingiu 75,59\%, no ano de 2010 apresentou taxa de mais de $84 \%$ e em 2012 alcançou 85\%, correspondendo a mais de 160,5 milhões de pessoas vivendo em cidades. 0 relatório Habitat da Organização das Nações Unidas (ONU, 2012) aponta que a taxa de urbanização brasileira atingirá 90\% em 2020.

A transição populacional, através do processo elencado de urbanização contemporânea, aponta a tendência mundial de busca pela satisfação de necessidades e aspirações, como também pela demanda de serviços, ambos disponibilizados nos centros urbanos. Ocorre que este processo é acompanhado pelo fenômeno de inchaço urbano, que ocorre de maneira desigual. Em suma, as melhores áreas urbanas são reservadas a elite econômica e para a população de baixa renda são fornecidas áreas impróprias à moradia digna e saudável. Estes fatores acabam por acarretar em um 
mesmo espaço urbano, grandes desigualdades e conflitos de interesses. Tais apontamentos trazem a tona o importante e difícil papel das esferas públicas de gestão das políticas públicas, que tem como tarefa principal garantir a qualidade de vida para seus cidadãos.

No que diz respeito ao conceito de qualidade de vida, tem-se que de maneira geral pode ser entendida como expressão que indica as condições de vida da população, envolvendo diferentes dimensões podendo ser analisada a partir do bem estar físico, mental, psicológico, emocional; também pelos relacionamentos sociais, pelas condições sociais de saúde, educação, meio ambiente, entre outros (OMS, 2002).

De acordo com a Carta de Ottawa (1986), a saúde e a qualidade de vida, se relacionam com as condições de vida, nos extratos sociais, econômicos, psicológicos, de justiça social e equidade; de modo que a "Cidade Inteligente" será gradativamente alcançada, através da busca contínua por melhorias na vida da população. Para que os resultados sejam alcançados é necessário conhecer os níveis de qualidade de vida que a cidade oferece aos moradores, considerando as diferenças setoriais e espaciais (acessibilidade). Dessa forma esses indicadores depois de mensurados e espacializados são vistos como parte de sistema holístico para monitorar o progresso das cidades (NAHAS, 2002).

0 uso de indicadores e índices é de fundamental importância para a construção e consolidação das Cidades Inteligentes, que têm sido difundidas na atualidade. De acordo com a Fundação Getúlio Vargas (FGV, 2015), as Cidades Inteligentes, ou Smart Cities, são sistemas de pessoas que se interagem com foco no desenvolvimento econômico e a melhoria da qualidade de vida. Essas interações são consideradas inteligentes porque fazem uso estratégico de infraestruturas e serviços e informação e comunicação com planejamento e gestão urbana para dar resposta às necessidades sociais e econômicas da sociedade (RBCIH, 2017).

\section{O Índice Mineiro de Responsabilidade Social na Microrregião de Araxá - MG}

A microrregião de Araxá (Figura 1), recorte abordado nesse estudo, encontra-se localizada na Mesorregião do Triângulo Mineiro e Alto Paranaíba e é composta pelos seguintes municípios: Araxá, Campos Altos, Ibiá, Nova Ponte, Pedrinópolis, Perdizes, Pratinha, Sacramento, Santa Juliana e Tapira. A tabela 1 apresenta a quantidade de população dos municípios e a taxa de urbanização, demonstrando que grande parte da população vive nas cidades.

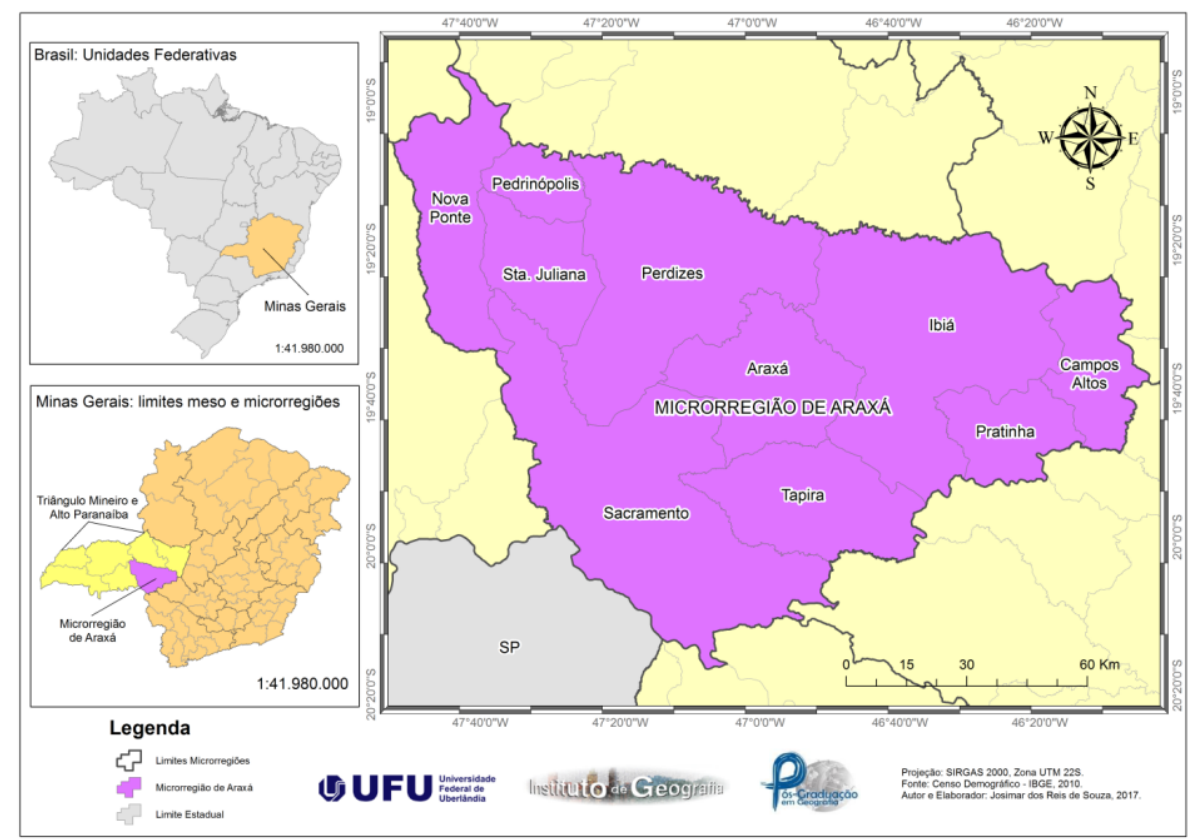

Figura 1 - Mapa de localização dos municípios da Microrregião de Araxá - MG Org.: SOUZA, 2017. 
A partir da necessidade de se criar instrumentos que auxiliassem no gerenciamento das regiões de planejamento, o governo do estado de Minas Gerais criou em 2004 o Índice Mineiro de Responsabilidade Social (IMRS), desenvolvido pela Fundação João Pinheiro (FJP, 2015). Desde então o índice é aplicado a todos os municípios de Minas Gerais, com resultados disponibilizados anualmente.

Tabela 1 - População Total e Taxa de Urbanização da Microrregião de Araxá - MG

\begin{tabular}{c|c|c|c|c|c}
\hline Município & $\begin{array}{c}\text { População } \\
\text { total }\end{array}$ & $\begin{array}{c}\text { Taxa de } \\
\text { Urbanização }\end{array}$ & Município & $\begin{array}{c}\text { População } \\
\text { total }\end{array}$ & $\begin{array}{c}\text { Taxa de } \\
\text { Urbanização }\end{array}$ \\
\hline Araxá & 101.136 & $98,62 \%$ & Perdizes & 15.484 & $72,18 \%$ \\
\hline Campos Altos & 15.078 & $91,06 \%$ & Pratinha & 3.485 & $57,23 \%$ \\
\hline Ibiá & 24.613 & $85,45 \%$ & Sacramento & 25.432 & $82,05 \%$ \\
\hline Nova Ponte & 14.241 & $87,11 \%$ & Santa Juliana & 12.702 & $87,11 \%$ \\
\hline Pedrinópolis & 3.638 & $84,56 \%$ & Tapira & 4.484 & $69,10 \%$ \\
\hline
\end{tabular}

Fonte: IBGE, 2010. Org.: SOUZA, 2017.

Através do IMRS, os municípios de Minas tem a oportunidade de avaliar o desempenho das políticas públicas nos últimos anos, como o intuito de corrigir falhar e/ou alcançar melhores resultados, como também usar os dados disponibilizados como subsídio ao planejamento das políticas públicas. Trata-se de grande volume dados disponibilizados, que podem ser tratados em seu valor real, ou através dos índices disponibilizados com a tratativa estatística já realizada pela Fundação João Pinheiro (com valores que compreendem entre zero e um).

A tabela 2 apresenta o resultado do IMRS da Microrregião de Araxá para os anos de 2002 e 2012. Foram escolhidos os indicadores para a análise: Saúde, Educação, Saneamento e Habitação, Renda e Emprego e Finanças Municipais.

Tabela 2 - Resultado do IMRS da Microrregião de Araxá - MG (Anos 2002 e 2012)

\begin{tabular}{c|c|c|c|c|c|c|c|c|c|c}
\hline \multirow{2}{*}{ Município/Ano } & \multicolumn{2}{|c|}{ Saúde } & \multicolumn{2}{c|}{ Educação } & \multicolumn{2}{c}{$\begin{array}{c}\text { Saneamento e } \\
\text { Habitação }\end{array}$} & \multicolumn{2}{c|}{$\begin{array}{c}\text { Renda e } \\
\text { Emprego }\end{array}$} & \multicolumn{2}{c}{$\begin{array}{c}\text { Finanças } \\
\text { Municipais }\end{array}$} \\
\cline { 2 - 13 } & $\mathbf{2 0 0 2}$ & $\mathbf{2 0 1 2}$ & $\mathbf{2 0 0 2}$ & $\mathbf{2 0 1 2}$ & $\mathbf{2 0 0 2}$ & $\mathbf{2 0 1 2}$ & $\mathbf{2 0 0 2}$ & $\mathbf{2 0 1 2}$ & $\mathbf{2 0 0 2}$ & $\mathbf{2 0 1 2}$ \\
\hline Araxá & 0,583 & 0,543 & 0,655 & 0,607 & 0,377 & 0,422 & 0,737 & 0,823 & 0,710 & 0,717 \\
\hline Campos Altos & 0,597 & 0,642 & 0,580 & 0,488 & 0,368 & 0,466 & 0,614 & 0,635 & 0,636 & 0,665 \\
\hline Ibiá & 0,742 & 0,714 & 0,622 & 0,521 & 0,472 & 0,504 & 0,690 & 0,740 & 0,703 & 0,777 \\
\hline Nova Ponte & 0,664 & 0,850 & 0,632 & 0,571 & 0,516 & 0,523 & 0,788 & 0,835 & 0,760 & 0,711 \\
\hline Pedrinópolis & 0,475 & 0,838 & 0,610 & 0,512 & 0,548 & 0,430 & 0,671 & 0,707 & 0,735 & 0,721 \\
\hline Perdizes & 0,668 & 0,741 & 0,591 & 0,557 & 0,398 & 0,593 & 0,694 & 0,793 & 0,663 & 0,681 \\
\hline Pratinha & 0,789 & 0,674 & 0,530 & 0,673 & 0,467 & 0,448 & 0,642 & 0,657 & 0,705 & 0,720 \\
\hline Sacramento & 0,670 & 0,759 & 0,631 & 0,517 & 0,574 & 0,529 & 0,727 & 0,768 & 0,773 & 0,749 \\
\hline Santa Juliana & 0,455 & 0,756 & 0,604 & 0,507 & 0,294 & 0,439 & 0,655 & 0,864 & 0,639 & 0,622 \\
\hline Tapira & 0,455 & 0,792 & 0,607 & 0,490 & 0,405 & 0,443 & 0,837 & 0,906 & 0,683 & 0,641 \\
\hline
\end{tabular}

Fonte: FJP, 2002 e 2012.

Org.: SOUZA, 2017.

A Figura 2 mostra a cartografia dos resultados do IMRS da Microrregião de Araxá para os anos de 2002 e 2012, de forma a possibilitar a visualização da evolução dos resultados entre o intervalo de 10 anos. Os resultados foram agrupados em cinco classes: Menor que 0,455 (Muito Baixo); 0,456 a 0,600 (Baixo); 0,601 a 0,700 (Médio); 0,701 a 0,800 (Alto); e Maior que 0,800 (Muito Alto). 


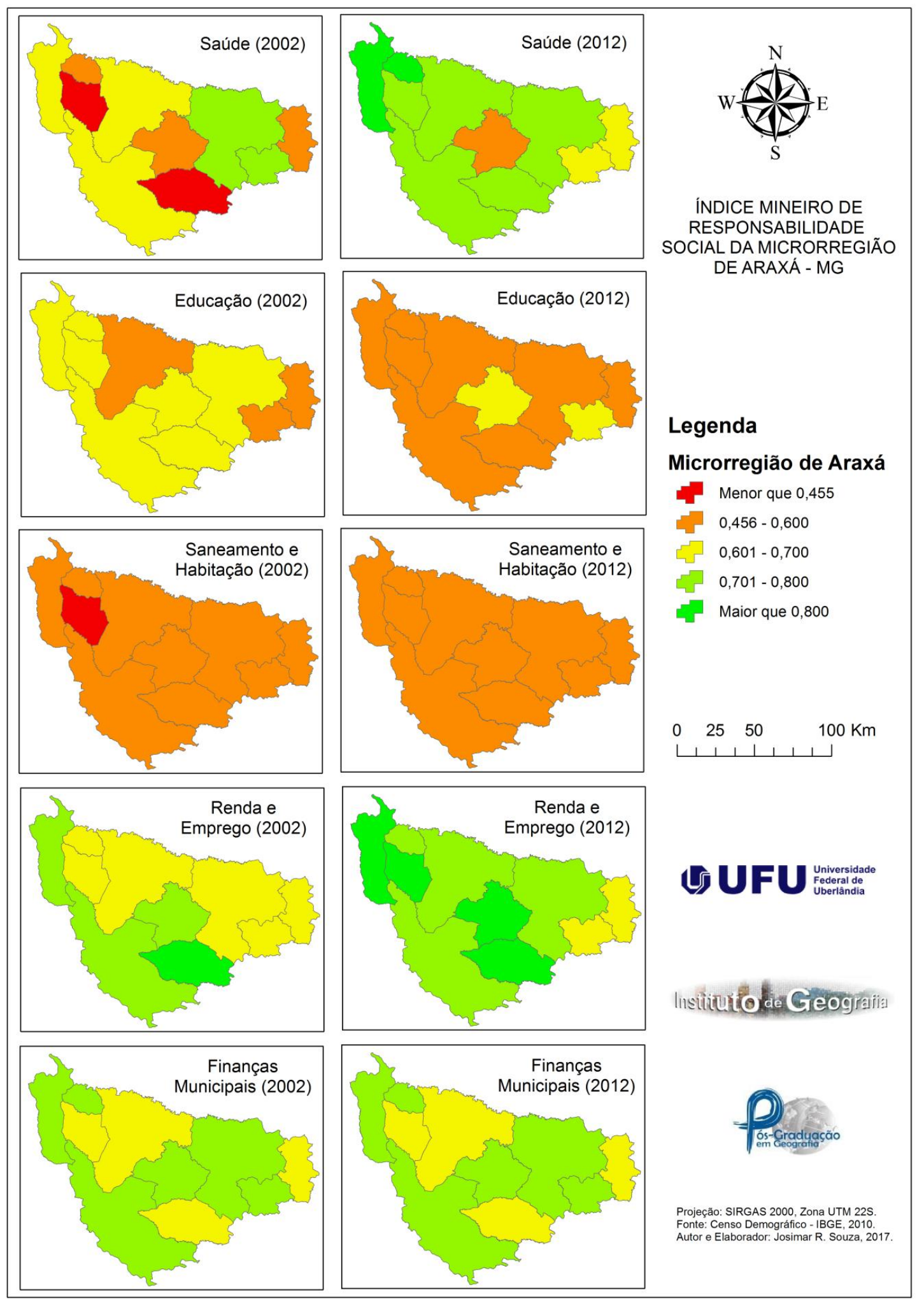

Figura 2 - Mapeamento do IMRS da Microrregião de Araxá - MG (Anos 2002 e 2012) Fonte: FJP, 2002 e 2012. Org.: SOUZA, 2017.

Para o IMRS Saúde a Fundação João Pinheiro utilizou as seguintes variáveis: taxa de mortalidade por doenças cérebro-vasculares da população de 45 a 59 anos; taxa de mortalidade perinatal; taxa de mortalidade por câncer de colo de útero na população feminina; cobertura vacinal de tetravalente em 
menores de um ano; proporção de internações por condições sensíveis à atenção primária; proporção de nascidos vivos cujas mães realizaram 7 ou mais consultas de pré-natal; proporção de óbitos por causas mal definidas; e cobertura populacional do Programa de Saúde da Família.

O gráfico 1 apresenta o resultado do IMRS Saúde. É possível verificar que no que diz respeito a saúde, os municípios estudados apresentaram em quase sua totalidade melhoria em seus indicadores. Entre as cidades que apresentaram piora nos resultados, cabe destacar Araxá, maior cidade da microrregião e Pratinha. Essa piora se deu, sobretudo, pelo incremento de população ocorrido nos últimos 10 anos, devido às atividades de mineradoras, instaladas na região (FJP, 2015).

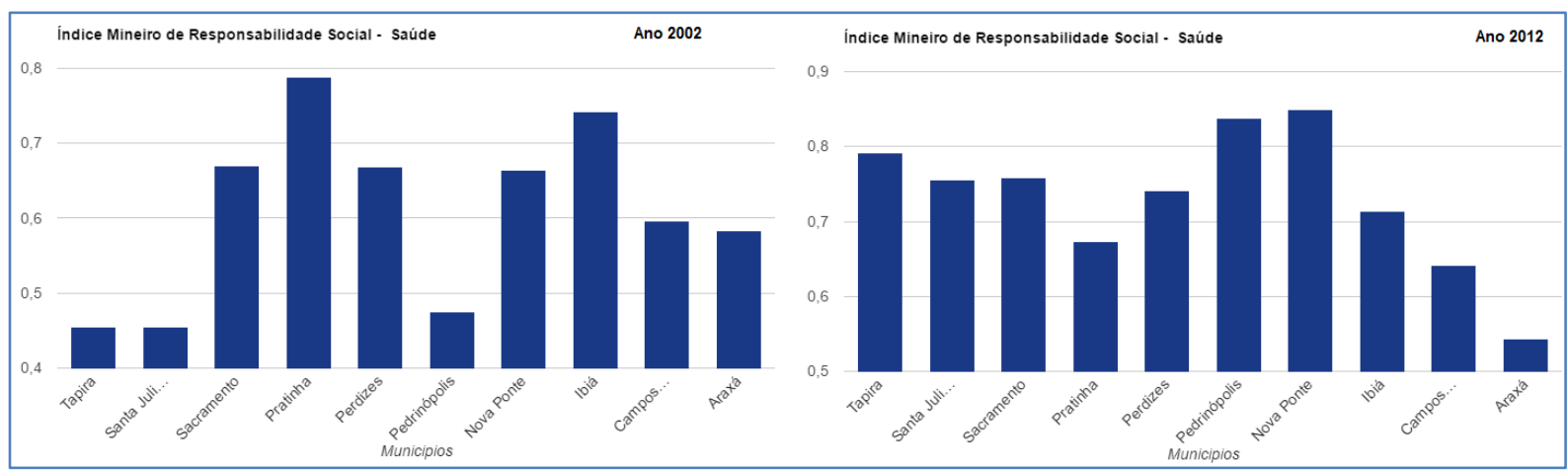

Gráfico 1 - IMRS Saúde da Microrregião de Araxá - MG (Anos 2002 e 2012)

Fonte: FJP, 2002 e 2012.

Adaptado por: SOUZA, 2017.

Para o IMRS Educação a Fundação João Pinheiro utilizou as seguintes variáveis: proporção de pessoas de 25 ou mais de idade com ensino fundamental completo; taxa de escolarização líquida do ensino fundamental; taxa de escolarização líquida do ensino médio; índice de qualidade geral da educação; e esforço orçamentário em atividades de educação.

0 gráfico 2 demonstra o resultado do IMRS Educação. É possível perceber o panorama geral de piora na qualidade da educação entre os municípios analisados. Apenas Pratinha apresentou melhora significativa (0,530 em 2002 para 0,673 em 2012). A piora verificada entre os anos analisados demonstra que as políticas educacionais empregadas nos últimos anos pelo governo estadual não foram suficientes para a sua melhoria. 0 fator motivador da piora se deu, sobretudo, pela insuficiência de recursos orçamentários para as atividades de educação (FJP, 2015).

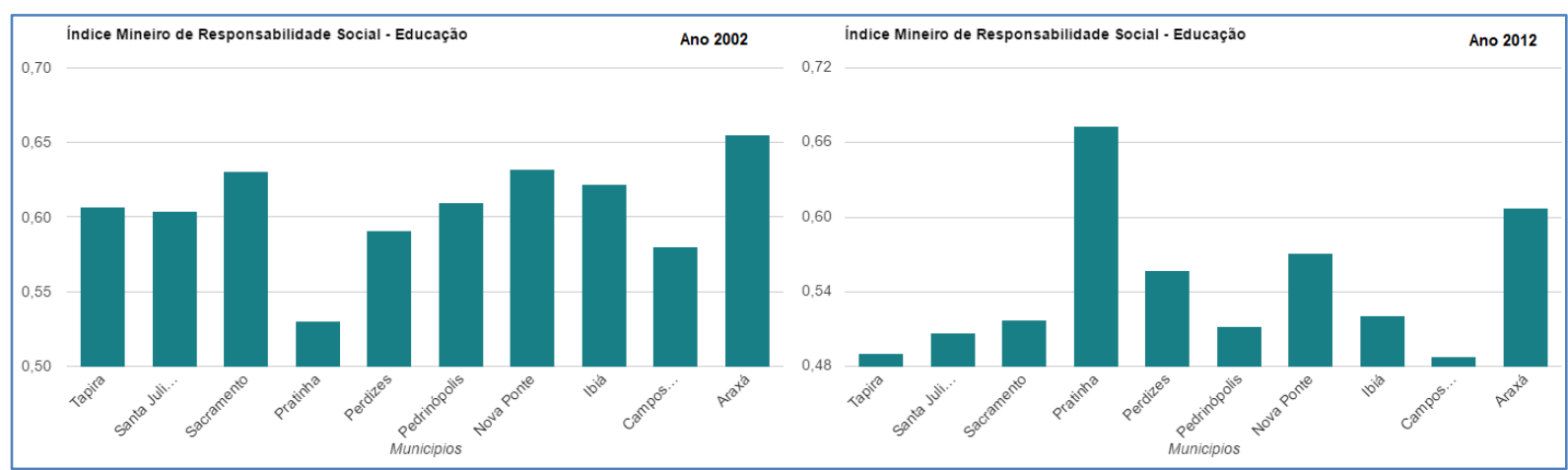

Gráfico 2 - IMRS Educação da Microrregião de Araxá - MG (Anos 2002 e 2012)

Fonte: FJP, 2002 e 2012.

Adaptado por: SOUZA, 2017.

Para o IMRS Saneamento e Habitação a Fundação João Pinheiro utilizou as seguintes variáveis: déficit habitacional relativo; percentual da população em domicílios com banheiro e água encanada; 
percentual da população em domicílios com coleta de lixo (direta e indireta); disposição final do lixo coletado; existência de Conselho Municipal de Saneamento ou afim; e esforço orçamentário em saneamento e habitação.

O gráfico 3 apresenta o resultado do IMRS Saneamento e Habitação. É claramente possível visualizar que no intervalo analisado, mesmo com os programas habitacionais implementados nos últimos anos pelos governos federal e estadual, não houve avanços significativos no indicador. Isso se deu, sobretudo, pelo insuficiente esforço orçamentário na melhoria do saneamento (FJP, 2015).

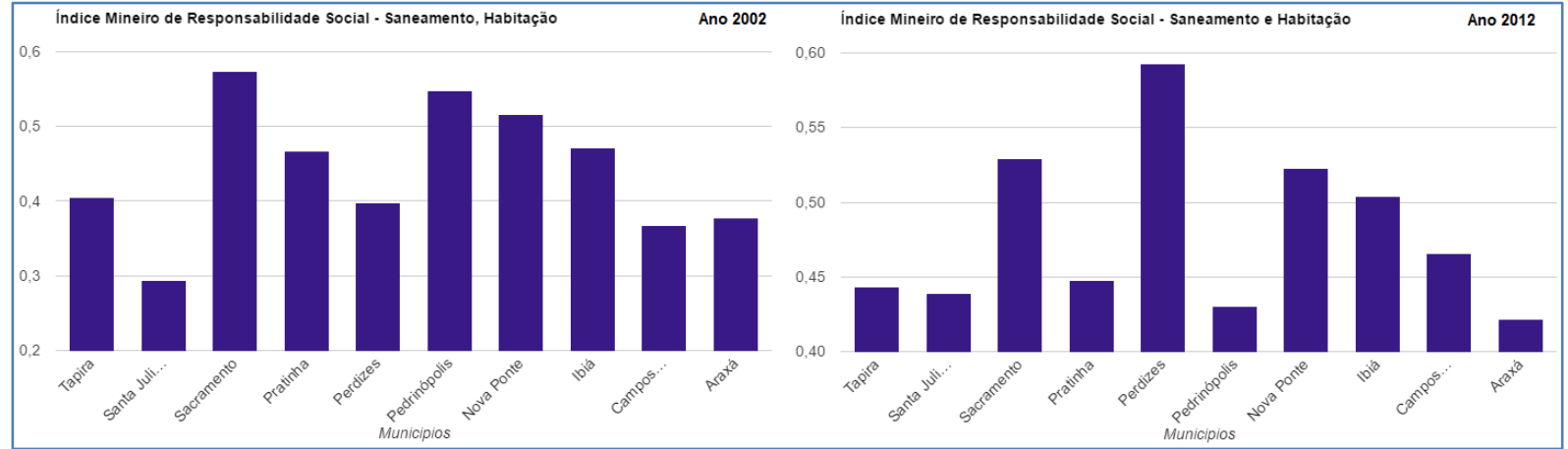

Gráfico 3 - IMRS Saneamento e Habitação da Microrregião de Araxá - MG (Anos 2002 e 2012)

Fonte: FJP, 2002 e 2012.

Adaptado por: SOUZA, 2017.

Para o IMRS Renda e Emprego a Fundação João Pinheiro utilizou as seguintes variáveis: rendimento médio do setor formal; taxa de emprego no setor formal; Produto Interno Bruto per capita; esforço de investimento; e gasto per capita total.

Através do gráfico 4 e com auxílio da tabela 1 e figura 2 é possível evidenciar que todos os municípios apresentaram evolução positiva na Renda e no Emprego. De acordo com a FJP (2015), essa melhora se deu, sobretudo, pelo aumento real do salário, pela geração de novos empregos e pelo aumento do nível de capacitação dos trabalhadores, que consequentemente, recebem maiores salários.

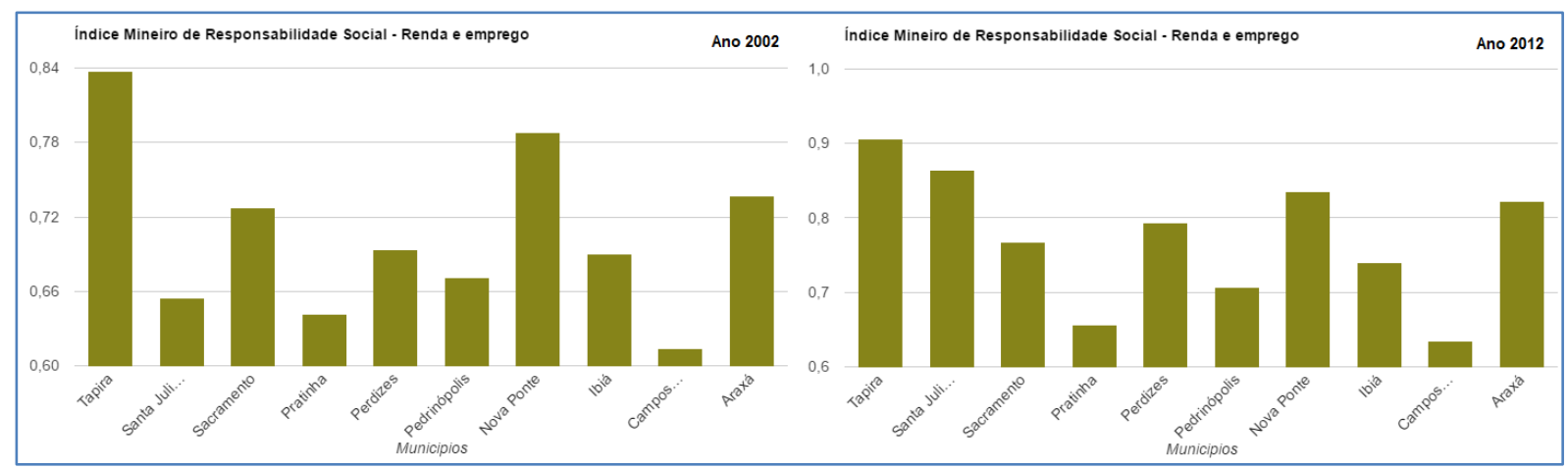

Gráfico 4 - IMRS Renda e Emprego da Microrregião de Araxá - MG (Anos 2002 e 2012)

Fonte: FJP, 2002 e 2012.

Adaptado por: SOUZA, 2017.

Para o IMRS Finanças Municipais a Fundação João Pinheiro utilizou as seguintes variáveis: índice de desenvolvimento tributário e econômico; receita corrente líquida per capita; endividamento participação da dívida consolidada líquida na receita corrente líquida; gastos com pessoal; gasto com Legislativo; custeio da máquina; e esforço de investimento. 
A partir do gráfico 5 é possível constatar que a maior parte dos municípios analisados apresentaram evolução positiva no indicador de Finanças Municipais. A exceção ficou com os municípios de Nova Ponte, Pedrinópolis, Sacramento, Santa Juliana e Tapira, entretanto, a retração do indicador foi pequena, podendo concluir que esses municípios apresentaram constância em suas finanças públicas municipais. De acordo com a FJP (2015), as finanças municipais tem relação direta com os valores recebidos pela prefeitura e a boa utilização dos seus recursos, sendo que o esforço de investimento o principal responsável pela melhoria do indicador de finanças municipais.

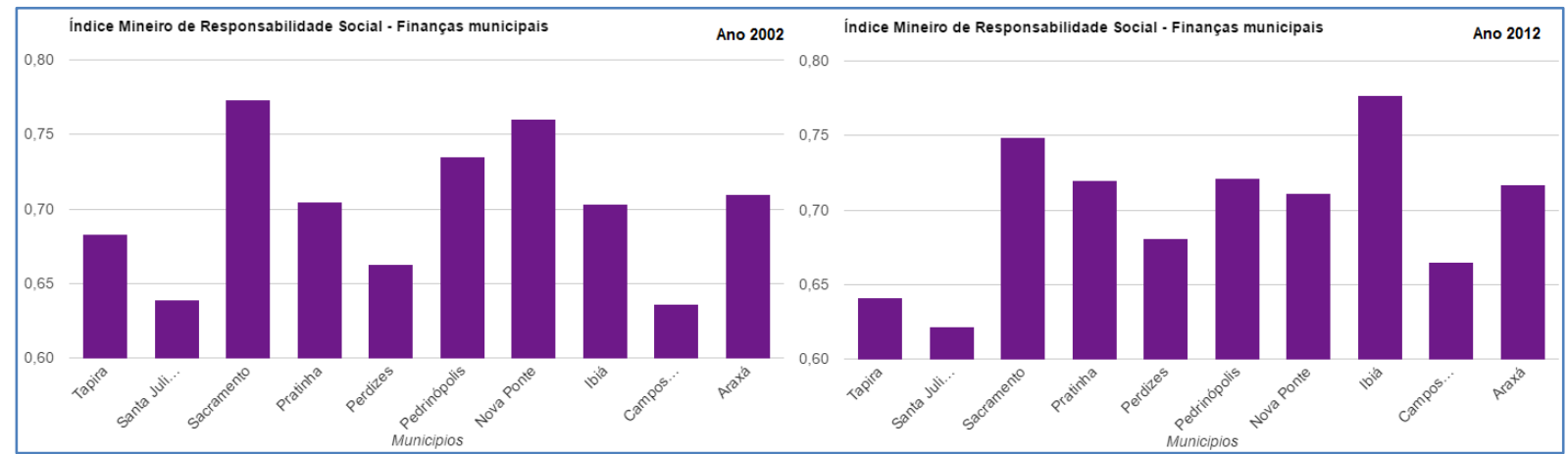

Gráfico 5 - IMRS Financias Municipais da Microrregião de Araxá - MG (Anos 2002 e 2012)

Fonte: FJP, 2002 e 2012.

Adaptado por: SOUZA, 2017.

Em suma, os dados do IMRS da microrregião de Araxá apresentaram melhorias nos indicadores de Saúde; Renda e Emprego e Finanças Municipais. Em contrapartida houve uma piora significativa nos indicadores de Educação e Saneamento e Habitação, sendo este motivado pelo quesito esforço orçamentário, no qual os investimentos públicos não foram suficientes para a superação dos problemas urbanos de educação e saneamento.

Sobre o Saneamento, tem-se que os municípios de pequeno porte têm dificuldades na implementação de políticas públicas voltadas a coleta seletiva de lixo, implantação de aterros sanitários, educação ambiental, entre outras políticas que possibilitem a melhoria da qualidade de vida da população. Em relação a educação, mesmo com os programas lançados pelo governo estadual, não houve avanços significativos. Fato motivado pela falta de capacitação dos professores, precariedade da infraestrutura das escolas e evasão escolar (FJP, 2015).

\section{Considerações Finais}

Os resultados apresentados, do levantamento das informações do IMRS da microrregião de Araxá, demonstra parte do grande acervo de informações já coletadas pela Fundação João Pinheiro e disponibilizadas gratuitamente para a realização de pesquisas e, sobretudo, para serem utilizadas pelos planejadores urbanos. A utilização desses dados é importante para a busca pela melhoria da qualidade de vida, foco da Rede Brasileira de Cidades Inteligentes e Humanas.

Os problemas inerentes da urbanização contemporânea devem ser analisados e solucionados. Para isso a consolidação de bancos de dados, como o IMRS, é de real importância para Minas Gerais e para o país. São através desses dados que a inteligência coletiva será construída, a busca de soluções serão possíveis e a melhoria da qualidade de vida atingirá patamares aceitáveis no Brasil. Cabe, portanto, a busca por estratégias de utilização de indicadores, a consolidação dos bancos de dados e sua utilização de fato, para se construir "Cidades Inteligentes". 


\section{Referências}

FUNDAÇÃO GETÚLIO VARGAS (FGV). O que é uma cidade inteligente?. São Paulo: FGV, 2017. Disponível em: http://fgvprojetos.fgv.br/noticias/o-que-e-uma-cidade-inteligente. Acesso em: Maio de 2017.

FUNDAÇÃO JOÃO PINHEIRO (FJP). Índice Mineiro de Responsabilidade Social dos anos de 2002 e 2012. Belo Horizonte: FJP, $2015 . \quad$ Disponível em: http://www.fjp.mg.gov.br/index.php/component/search/imrs. Acesso em: Maio de 2017.

INSTITUTO BRASILEIRO DE GEOGRAFIA E ESTATÍSTICA (IBGE). Censo Demográfico de 2010. Rio de Janeiro: IBGE, 2011. Disponível em: http://censo2010.ibge.gov.br/. Acesso em: Maio de 2017.

INSTITUTO BRASILEIRO DE GEOGRAFIA E ESTATÍSTICA (IBGE). IBGE Cidades - Informações sobre as cidades da Microrregião de Araxá. Rio de Janeiro: IBGE, 2010. Disponível em: http://www.cidades.ibge.gov.br/xtras/home.php. Acesso em: Maio de 2017.

LIMA, S. C. A construção de Cidades Saudáveis a partir de estratégias de promoção da saúde. LIMA, S. C.; COSTA, E. M. (Orgs.). Construindo Cidades Saudáveis. Uberlândia: Assis Editora, 2013. p. 13-44.

NAHAS, M. I. P. Bases teóricas metodologia de elaboração e aplicabilidade de indicadores intraurbanos na gestão municipal da qualidade de vida urbana em grandes cidades: o caso de Belo Horizonte. 2002. 373 f. Tese (Doutorado em Geografia) - Universidade Federal de São Carlos, São Carlos, 2002.

ORGANIZAÇÃO DAS NAÇÕES UNIDAS (ONU). Estado das Cidades da América Latina e Caribe. Nova Iorque: ONU, 2012. Disponível em: http://es.unhabitat.org/. Acesso em: Maio de 2017.

ORGANIZAÇÃO MUNDIAL DE SAÚDE (OMS). Carta de Otawa da Primeira Conferência Internacional de Saúde. Otawa: $\quad 1986 . \quad$ OMS, Disponível em: http://bvsms.saude.gov.br/bvs/publicacoes/carta_ottawa.pdf. Acesso em: Maio de 2017.

REDE BRASILEIRA DE CIDADES INTELIGENTES \& HUMANAS (RBCIH). Projeto Cidades Inteligentes \& Humanas. Natal: RBCIH, 2017. Disponível em: http://redebrasileira.org/. Acesso em: Maio de 2017.

SANTOS, M. A urbanização brasileira. São Paulo: HUCITEC, 1993. 